\title{
Correction to: FDA and EMA Biosimilar Approvals
}

Emily H. Jung, A. $B^{7}$, Ameet Sarpatwari, Ph.D. J.D', Aaron S. Kesselheim, M.D., J.D., M.P.H $H^{1,1}$, and Michael S. Sinha, M.D., J.D., M.P.H $H^{1,2}$

'Program on Regulation, Therapeutics, and Law (PORTAL), Division of Pharmacoepidemiology and Pharmacoeconomics, Department of Medicine, Brigham and Women's Hospital and Harvard Medical School, Boston, MA, USA; ${ }^{2}$ Harvard-MIT Center for Regulatory Science, Harvard Medical School, Boston, MA, USA.

$\mathrm{J}$ Gen Intern Med

DOI: $10.1007 / \mathrm{s} 11606-019-05558-7$

() Society of General Internal Medicine 2019

Correction to: J Gen Intern Med https://doi.org/10.1007/s11606-019-05408-6

This paper published with several formatting errors. They have been corrected and the paper has re-published.

Corresponding Author: Ameet Sarpatwari, Ph.D. J.D; Program on Regulation, Therapeutics, and Law (PORTAL), Division of Pharmacoepidemiology and Pharmacoeconomics, Department of Medicine Brigham and Women's Hospital and Harvard Medical School, Boston, MA, USA (e-mail: asarpatwari@bwh.harvard.edu).

Publisher's Note Springer Nature remains neutral with regard to jurisdictional claims in published maps and institutional affiliations.

The online version of the original article can be found at https://doi.org/10. 1007/s11606-019-05408-6 